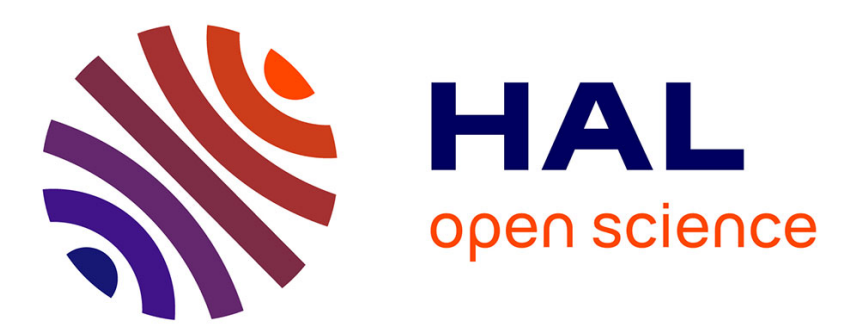

\title{
La politisation du religieux en modernité, edited by Nathalie Caron et Guillaume Marche
}

\author{
Laurence Lux-Sterritt
}

\section{To cite this version:}

Laurence Lux-Sterritt. La politisation du religieux en modernité, edited by Nathalie Caron et Guillaume Marche. Social sciences and missions/Sciences sociales et missions, 2017, 30 (1-2), pp.188 - 190. 10.1163/18748945-03001014 . hal-01628963

\section{HAL Id: hal-01628963 https://hal.science/hal-01628963}

Submitted on 20 Jan 2018

HAL is a multi-disciplinary open access archive for the deposit and dissemination of scientific research documents, whether they are published or not. The documents may come from teaching and research institutions in France or abroad, or from public or private research centers.
L'archive ouverte pluridisciplinaire HAL, est destinée au dépôt et à la diffusion de documents scientifiques de niveau recherche, publiés ou non, émanant des établissements d'enseignement et de recherche français ou étrangers, des laboratoires publics ou privés. 


\section{Nathalie Caron et Guillaume Marche (dir.), La politisation du religieux en modernité, postface de Jean-Paul Willaime, Collection Sciences des religions, Presses universitaires de Rennes, 2015, 201 p. ISBN 978-2753535695. 16€}

Dans cet ouvrage collectif publié aux Presses universitaires de Rennes, Nathalie Caron et Guillaume Marche réunissent onze chapitres qui examinent le rapport complexe entre religieux et politique dans les sociétés modernes des mondes anglophones. Leur angle d'approche privilégie un mouvement qui prend le religieux comme point de départ pour aller vers le politique, à contrepied de nombre d'études où c'est au contraire le politique qui vient à la rencontre du religieux. L'introduction constate que, si la sécularisation progressive mise en place à l'ère moderne n'a pas amené à la disparition du religieux ni même à son retrait de la sphère publique vers la sphère privée, elle a néanmoins fortement modifié les contours du religieux, et son rapport au politique. L'ouvrage ne se consacre pas principalement au rapport entre Églises et états, mais fait la part belle à l'engagement religieux et aux diverses formes de mobilisation qui articulent le sentiment religieux et le positionnement politique.

Ce recueil a clairement été conçu avec le souci de décloisonner autant les siècles que les aires géographiques et les disciplines. À une époque où ce thème complexe, voire épineux, est d'une brûlante actualité, les auteurs croisent leurs regards de civilisationnistes, d'historiens, de sociologues mais aussi — ce qui est moins courant-de juristes, inscrivant cet ouvrage dans une véritable perspective interdisciplinaire. En outre, les articles étudient la politisation du religieux sur les cinq derniers siècles avec, pour les siècles plus lointains, des études de cas telles les réécritures de la liturgie henricienne dans les années 1530 (Aude de Mézerac-Zanetti), l'anticatholicisme (Gaby Mahlberg) ou la conscience religieuse (Cyril Selzner) durant les années de guerres civiles et de république en Angleterre, une analyse de la théorie politique de Thomas de Quincey (Frédéric Slaby), une étude des conférences de Hugh Price Hughes (Emmanuel Roudaut) et, pour les États-Unis, un article sur l'ordre moral protestant dans les Églises du Sud au XIX ème siècle (Laura Rominger Porter). Pour les siècles plus récents, et jusqu'à l'ultramodernité, le volume regroupe une contribution sur l'Église catholique en Irlande (Déborah Vandewoude), deux articles sur la Nouvelle-Zélande, l'un analysant «La politisation des questions sexuelles dans la construction des identités protestants » (Gwendoline Malogne-Fer) et l'autre théorisant les «marches pour Jésus » des protestants évangéliques dans le cadre de la campagne qui remet en question le droit des parents de gifler leurs enfants (Yannick Fer), et deux articles sur les États-Unis, l'un sur la sacralité du Premier amendement et le droit fiscal (Nina J. Crimm et Laurence H. Winer) et l'autre sur la réforme démocrate du système de santé et la gauche religieuse (Amandine Barb).

Cette large perspective permet une intéressante mise en regard de thèmes qui se font écho à travers les siècles et de part les continents. Les lecteurs trouveront matière à réflexion, par exemple, quant au rôle du catholicisme dans le monde britannique depuis la Réforme. L'article de Gaby Mahlberg remet en question l'anticatholicisme comme constituant essentiel de la construction d'une identité nationale anglaise aux XVIème et XVIIème siècles, et va jusqu'à évoquer un « mythe » de l'anticatholicisme républicain, non sans faire parfois quelques amalgames qui mériteraient une remise en contexte plus exacte. L'une des conclusions de cet article est que «le degré auquel l'anticatholicisme a 
dominé tant la pensée républicaine anglaise du XVII siècle que l'expérience anglaise dans son ensemble a été largement exagéré » (26) ; cette une affirmation au caractère généraliste demande à être étayée plus avant, et au-delà de quelques cas particuliers. La contribution de Déborah Vandewoude, elle, montre que le catholicisme demeure un élément intrinsèque de l'identité nationale irlandaise contemporaine ; cet article illustre finement comment l'Église catholique irlandaise cherche à restaurer son image et son assise sur la société laïque par l'intermédiaire de stratégies de profanisation mises au service du sacré. Les trois articles qui étudient l'importance des actions spontanées de groupes dont la ferveur religieuse infléchit la politique familiale et morale de la Nouvelle-Zélande des XXème et XXIème siècle et des États-Unis du XIXème fournissent également de très intéressantes passerelles entre eux, et des liens se tissent ainsi, au fil de la lecture, entre les aires culturelles américaines, européennes et océaniennes. Il aurait été fascinant d'ajouter des études provenant de pays anglophones d'Afrique et d'Asie, pour enrichir encore cette perspective de la politisation du religieux dans les mondes anglo-saxons.

Le parti-pris de la longue durée, comme c'est souvent le cas, est aussi porteur de richesse qu'il est délicat à mettre en œuvre: une telle variété temporelle enrichit l'ouvrage, mais le rend également plus difficile à organiser. L'équilibre chronologique entre les parties est délicat à établir, et tandis que la première partie (« Discours ») fait la part belle à la période XVIème_XVIIIème siècles, la troisième partie ("Actions»), au contraire, porte beaucoup plus fortement sur l'ère des XIXème-XXIème siècles. En outre, dans la deuxième partie («Organisation»), les lecteurs peuvent être surpris de passer de la subtile étude de l' «Approche liturgique de la suprématie royale sous le règne d'Henri VIII » (par Aude de Mézerac-Zanetti) à la non moins stimulante analyse de « La politisation des questions sexuelles dans les identités protestantes en Nouvelle-Zélande » au XXIème siècle (par Gwendoline Malogne-Fer). Ces deux chapitres, tous deux des moments forts de l'ouvrage, tant ils sont révélateurs et de haute tenue, sont si éloignés thématiquement, chronologiquement et culturellement qu'il est un peu déstabilisant de les trouver ainsi à la suite l'un de l'autre. Les lecteurs apprécieront la qualité des articles et sauront reconnaître là l'une des difficultés inhérentes aux ouvrages dont le souci est d'envisager un concept sur la longue durée.

Le recueil se termine sur une postface de Jean-Paul Willaime qui place parfaitement les concepts de religieux et de politique dans un cadre théorique et conceptuel où se côtoient, entre autres, les travaux d'Émile Durkheim, de Max Weber ou de Paul Ricœur. L'auteur y montre de façon magistrale que la notion de sacré n'appartient exclusivement ni au religieux, ni au politique, mais émerge plutôt de leur entrecroisement, lors de longs processus de sacralisation ou de profanation. Cette postface inscrit la réflexion de tout le recueil dans le paradigme non de la postmodernité mais de l'ultramodernité, que l'auteur décrit comme «l'état présent de la modernité occidentale, état qui, loin de signifier une sortie de la modernité [...] incarne au contraire une radicalisation de la modernité dans la mesure où celle-ci ne démythologise pas seulement les religions, mais aussi les idéologises séculières ». (182) Cette superbe postface est le point d'orgue d'un ouvrage ambitieux, qu'elle conclut magnifiquement.

Laurence Lux-Sterritt

Aix Marseille univ, LERMA, Aix-en-Provence, France 